\title{
Thermal Management Opportunity on Lubricant Oil to Reduce Fuel Consumption and Emissions of a Light-Duty Diesel Engine
}

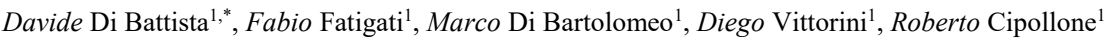 \\ ${ }^{1}$ University of L'Aquila, Department of Industrial and Information Engineering and Economics, 67100, L'Aquila, Italy
}

\begin{abstract}
The high viscosity of the lubricant oil in internal combustion engines at cold starts is responsible for poor friction reduction and inadequate thermal stabilization of metallic masses and represents a major bottleneck in the efforts to reduce specific fuel consumption and pollutant emissions. Consequently, the possibility of integrating techniques for proper thermal management of the lubricant oil on internal combustion engines is of utmost importance to both homologation and daily on-road operation. Main options for reducing the warm-up time for the engine lubricant are the upgrade of the engine cooling and lubricating circuits, dedicated heating, different flow management of the oil/coolant heat exchanger, a renewed design of the oil sump or a thermal storage section to increase the oil temperature in the early phases of the warm up. The paper presents a new opportunity, using a hot storage medium to heat up the oil in the early phase of a driving cycle. A certain quantity of hot water, so, is stored in a tank, which can be used to warm up the lubricating oil when the engine is started up. The heating of this service water can be done by using exhaust gas heat, which is always wasted in the atmosphere. The activity is realized on an IVECO 3.0 L light-duty diesel engine, during a transient cycle (NEDC) on a dynamometric test bench. The benefits in terms of both fuel consumption and $\mathrm{CO}_{2}$ emissions reduction. The characterization of the backpressure associated with an eventual additional heat exchangers and the more complex layout of the oil circuit is assessed, as well as the transient effects produced by the faster oil warm-up and oil-coolant interaction on the engine thermal stabilization.
\end{abstract}

\section{Introduction}

Air quality protection, primarily via the reduction in greenhouse gases emissions, is a priority for legislation worldwide. Emissions regulations currently in place for the transportation sector drive present and future technological development and conjugate the objectives of fuel saving to those of a higher vehicle - namely, engine - efficiency and lower overall pollutant emissions [1].

The expectation on highly performing vehicles rebounds on the efforts to develop and implement improved testing procedures on a global basis, which led, among others, to the introduction of the World Harmonized Light Vehicle Test Procedure - WLTP for engine homologation and the setting of a new, more demanding RDE (Real Driving Emission) cycle for major pollutants (i.e., HC, CO, NOx, and PM) assessment. Globally, the transportation sector accounts for 30$35 \%$ of the overall $\mathrm{CO}_{2}$ emissions. Regarding the EU scenario, car and van fleets and heavy-duty vehicles (e.g., buses and trucks) are responsible for an average of $15 \%$ and $5 \%$ of the total $\mathrm{CO}_{2}$ emissions, respectively $[1,2]$.

Consequently, binding emissions limitations apply to light-duty passenger cars and commercial vehicles, resulting in the requirement for Euro 6 vehicles to comply with the $95 \mathrm{gCO}_{2} / \mathrm{km}$ threshold. In addition, ambitious goals have been set by EU policymakers, for the short run, on both new cars and vans, with an expected $37,5 \%$ and $31 \%$ emissions reduction, with respect to the 2021 value, to be achieved by $2030[2,3]$.

The complexity and multi-faceted regulatory scenario on the one hand, and the increasingly more stringent requirements on transportation technology, still largely dependent on the traditional internal combustion engine, whose improvement is already at the asymptote, suggest the importance that even the slightest gain on fuel consumption could have on the market success of both diesel and gasoline engines in the years to come.

An extensive literature proves that the largest share of $\mathrm{CO}_{2}$ emissions from internal combustion engines takes place at cold starts and in operating conditions similar to those in the first three quarters of engine homologation cycles, i.e., when both the power unit and the aftertreatment are inefficiently operated, due to torque and engine RPM variation from the steady state $[4,5]$. In such conditions, the fast warm-up of lube oil up to its optimum operating temperature is addressed as an effective option for reducing the friction mean effective pressure (FMEP), particularly between the rings and cylinder liner and in the crankshaft bearings $[6,7,8]$

*Corresponding Author: davide.dibattista@univaq.it 
Since the engine parts the oil gets in contact with, are still not thermally stabilized, the oil heating by direct contact (conduction and convection with the metallic masses) is not possible. Moreover, any attempt to harvest thermal energy for lubricant heating purposes in such phases is limited by the occurrence of misfiring and incomplete combustions, plus the inefficient charge motion inside the cylinder $[9,10,11]$ that results in a heat release rate below expected theoretical values. As a matter of fact, in these phases, the available thermal power from the combustion process must be employed entirely to raise the temperature of the combustion chamber and the piston and to set more favorable conditions to subsequent combustions and the only chance to warm the oil up is by feeding it with thermal energy in a dedicated onboard heating circuit, that would necessarily integrate the serial ones for lubricant circulation and cooling.

The implementation of enhanced techniques for proper thermal management and fast warm-up of the lube oil can definitely rely on the definition of lumped parameters models of the engine, providing preliminary results in terms of the relative advantage of an electrical pump over a mechanical one for coolant circulation [12, 13], pressure drops and overall performance of the modified lubricant circuit [14, 15], optimum oil sump design for fast thermal stabilization [16], onboard thermal storage for lubricant heating purposes $[17,18]$. An increasing interest is currently drawn by the option of integrating on-board thermal storage units to standard layouts $[19,20]$, to feed thermal energy to the lubricant at cold starts, when no other heat source is ready and immediately exploitable.

Aside from components down-sizing and down-weighting requirements to meet, the idea of harvesting thermal energy for optimum oil thermal management calls for the proper plant set-up, whose characteristics mostly depend on (i) the heat transfer fluid [21, 22], (ii) the option of direct electrical heating of the storage unit [23] and the room offered by exhaust gases [24], (iii) the pressure losses in the oil heating circuit and (iv) power absorption for circulation, based on the selected pump technology [25]. An in-depth experimental activity is then crucial to properly account for the complex phenomenology controlling the engine operation during initial transients $[26,27]$ and to allow the assessment of both the actual thermal availability to oil and the benefit in terms of friction reduction, fuel saving and enhanced emissions performance.

The present paper deals with the experimental assessment of the option of oil heating via on-board stored thermal energy by water. The heat is harvested in a shell and tube heat exchanger from exhaust gases during previous driving cycles, provided to the water, and stored inside a thermally insulated unit, until the next engine start. The experimental validation is carried out on a light-duty diesel engine on a dynamometric test bench, to fully reproduce the NEDC homologation cycle and close-to-normal driving conditions. The experimental dataset supports the definition of a proper control strategy for fuel saving and emissions reduction.

\section{Materials and Methods}

An IVECO F1C 3.0L turbocharged diesel engine is operated according to the NEDC homologation cycle on a dynamic test bench. In standard setups, the lubricant temperature is controlled by phasing the oil adduction to a flat plate heat exchanger, right downstream the pump and upstream the engine (Figure 1): the cooling fluid draws thermal energy from the lube oil during the whole driving cycle, independently on the actual need for oil cooling (i.e., on the oil actual operating temperature).

Table 1. reference engine and vehicle specs.

\begin{tabular}{|l|c|c|c|}
\hline Displaced volume & $2998 \mathrm{cc}$ & Number of cylinders & 4 in line \\
\hline Stroke & $104 \mathrm{~mm}$ & Maximum power & $130 \mathrm{~kW} @ 3250 \mathrm{RPM}$ \\
\hline Bore & $95.8 \mathrm{~mm}$ & Maximum torque & $400 \mathrm{Nm} @ 2000 \mathrm{RPM}$ \\
\hline Connecting rod & $255 \mathrm{~mm}$ & Supercharging & Variable Geometry Turbine \\
\hline Compression ratio & $19: 1$ & $\mathrm{CO}_{2}$ rated emissions & $260 \mathrm{~g} / \mathrm{km}$ \\
\hline Number of valves & 16 & & \\
\hline
\end{tabular}

Since the cooling system is designed for proper oil thermal stabilization during normal and continuous engine operation, it is oversized for oil thermal management at cold starts. As a matter of fact, it slows down the reaching of the designed value of oil viscosity, hence increasing frictional losses. More in detail, the lubricant circuit features a chaindriven gear-type oil pump - linear characteristic with RPM and a $55 \mathrm{~L} / \mathrm{min}$ maximum volumetric flowrate - that circulates oil from a $7 \mathrm{~L}$ sump. A thermostatic valve regulates the coolant flow to the radiator and allows to by-pass it when no heat removal on the coolant is needed. 


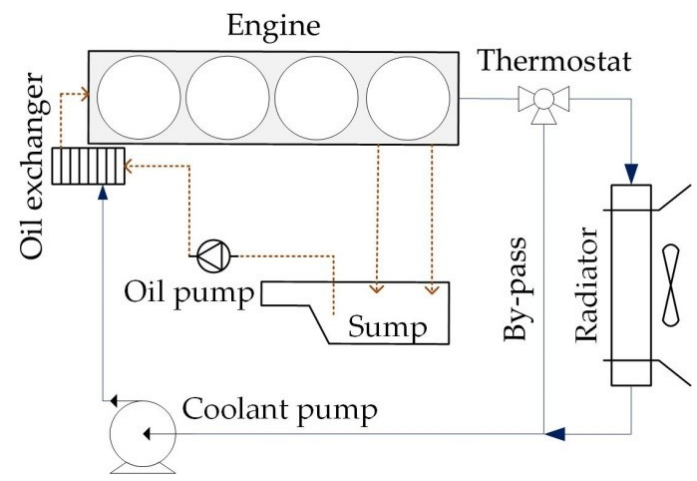

Fig. 1. Standard oil cooling circuit of the reference engine [28]

In order to accelerate the oil warm up at cold starts, an additional hot source is needed. It has been identified in a thermal storage section ( $5 \mathrm{~L}$ of hot water in the tank), which can be accumulated from a previous utilization of the engine. The work aims to use this hot source in the very early phase of the starting of the engine, in order to suddenly give the thermal energy owned by the storage to the lubricant oil. Therefore, the oil path was modified, with the addition of an oil/water heat exchanger and an exhaust heat recovery section: as the water $(5 \mathrm{~L})$ temperature decreases due to the cycleby-cycle heat release to oil, the thermal power recovered from exhaust gases allows the restoring of water temperatures suitable for oil heating (Figure 2). After being filtered, the lubricant can either (i) reach or (ii) bypass the coolant heat exchanger, and (iii) engage the heat exchange with water, based on whether the oil is already at the optimum $80{ }^{\circ} \mathrm{C}$ temperature or not.

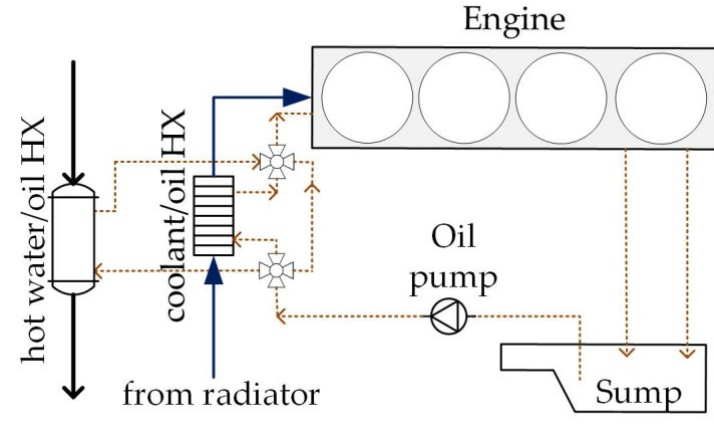

(a)

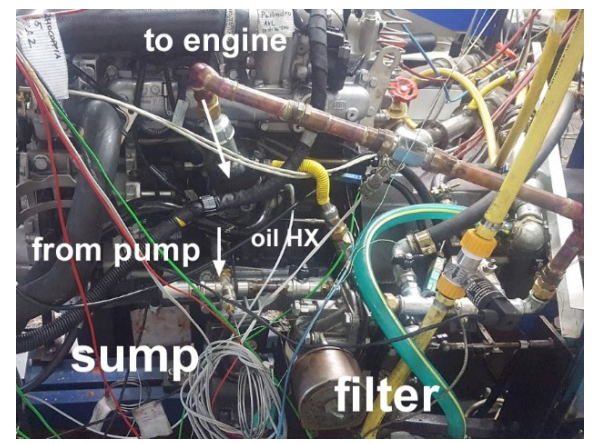

(b)

Fig. 2. Modified oil circuit - Schematics (a) and picture of the bench built (b)

The detailed water circuit has been sketched in Figure 3 a) and built in the engine test bench as represented in Figure 3 b). The water circuit is composed of an insulated tank, which is the main thermal storage device, a circulating pump, the heat exchanger between hot water and lubricating oil, and the second heat exchanger between the exhaust gases and the service water, which ensures an upper thermal source to the water, in order to enhance the warming up of the oil and, mainly, to reheat the water when the thermal regimentation is reached and, so, making available the hot thermal storage for next starting. Temperatures are measured in each node of the circuit, while a turbine flow meter is used to assess the water flow rate. A thorough thermal and hydraulic characterization of the oil circuit was possible via the monitoring of both temperatures and pressures, according to the schematics in Figure 2 and specifications - types of sensors and uncertainties - in Table 2. 
Table 2. Main sensors specifications

\begin{tabular}{ccc}
\hline Variable & Sensor type & Accuracy \\
\hline Temperature & $\begin{array}{c}\text { K-type } \\
\text { thermocouple }\end{array}$ & $\pm 2,2{ }^{\circ} \mathrm{C}$ \\
Pressure & GEMS2200 & $\pm 0,1 \mathrm{bar}$ \\
$\begin{array}{c}\text { Volumetric } \\
\text { flowrate }\end{array}$ & $\begin{array}{c}\text { Turbine-type } \\
\text { sensor }\end{array}$ & $\pm 0.5 \%$ \\
$\begin{array}{c}\text { Fuel } \\
\text { consumption }\end{array}$ & $\begin{array}{c}\text { AVL 733s fuel } \\
\text { balance }\end{array}$ & $\begin{array}{c} \pm 0,05 \% \\
\text { measured value }\end{array}$ \\
\hline
\end{tabular}

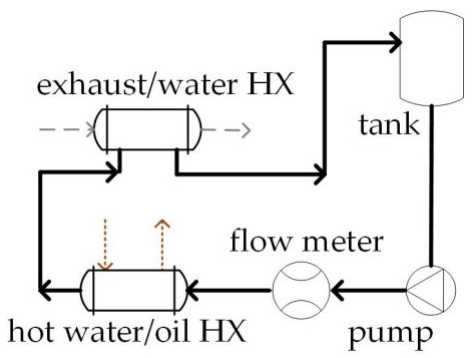

(a)

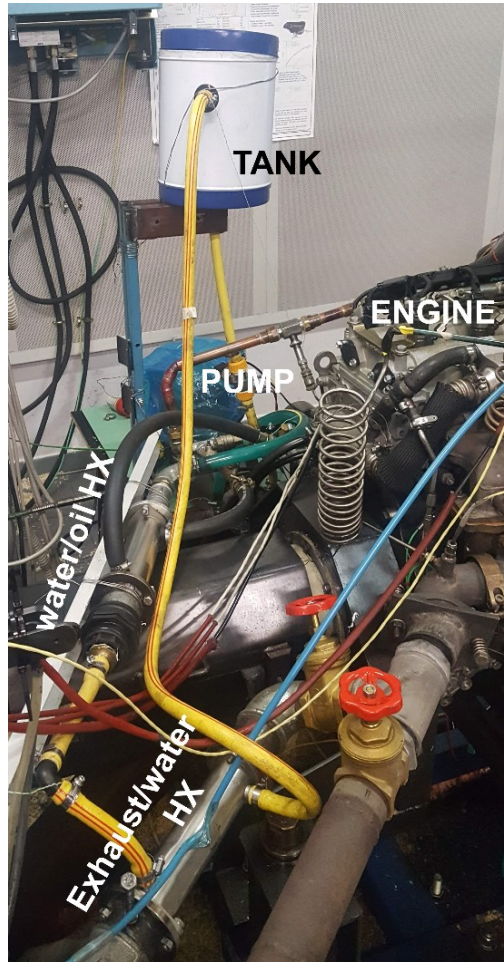

(b)

Fig. 3: auxiliary water circuit for hot thermal storage exploitation: (a) layout sketch and (b) experimental arrangement

\section{Experimental Characterization}

The reconstruction of the thermal profiles was performed, during a whole NEDC homologation cycle, on the water stream (for lubricant heating), the engine coolant, and the oil itself. The analysis of the temperature profiles for water in each side of the devices which compose the water circuit (Figure 4) allows the assessment of the actual feasibility of oil heating at cold starts: the initial temperature of the water is close to $70^{\circ} \mathrm{C}$, which is reasonable considering the thermal dispersion between the previous run of the engine and the actual start, although the tank is insulated.

Exhaust gases flowing through the heat exchanger seem to give additional aid to fulfill the purpose of warming up the water, prior it flows back into the storage unit and eventually is employed for oil heating, already after $50 \mathrm{~s}$. The water starts at $68-70{ }^{\circ} \mathrm{C}$, loses $10{ }^{\circ} \mathrm{C}$ during the first $60 \mathrm{~s}$, when exhaust gases do not provide any thermal back up to the water itself and metallic masses within the heat exchanger are cold. As the engine warms up and the combustion temperature inside the cylinders increases, exhaust gases start re-integrating the water thermal power, lost to the surroundings and lubricant oil, and a continuously growing trend is appreciated until the water pump is switched off, little after $800 \mathrm{~s}$, when oil temperature and water one are similar.

The temperature fluctuations at the tank inlet are dampened, due to the intrinsic larger thermal inertia of the water inside the storage unit: the temperature of water at the tank outlet is always $10-15{ }^{\circ} \mathrm{C}$ lower than the one at the tank inlet and never exceeds $90{ }^{\circ} \mathrm{C}$. Due to the initial transient, a temperature difference-driven heat exchange between the water and the oil starts at $100 \mathrm{~s}$ and continues until the water is fed by the pump. 


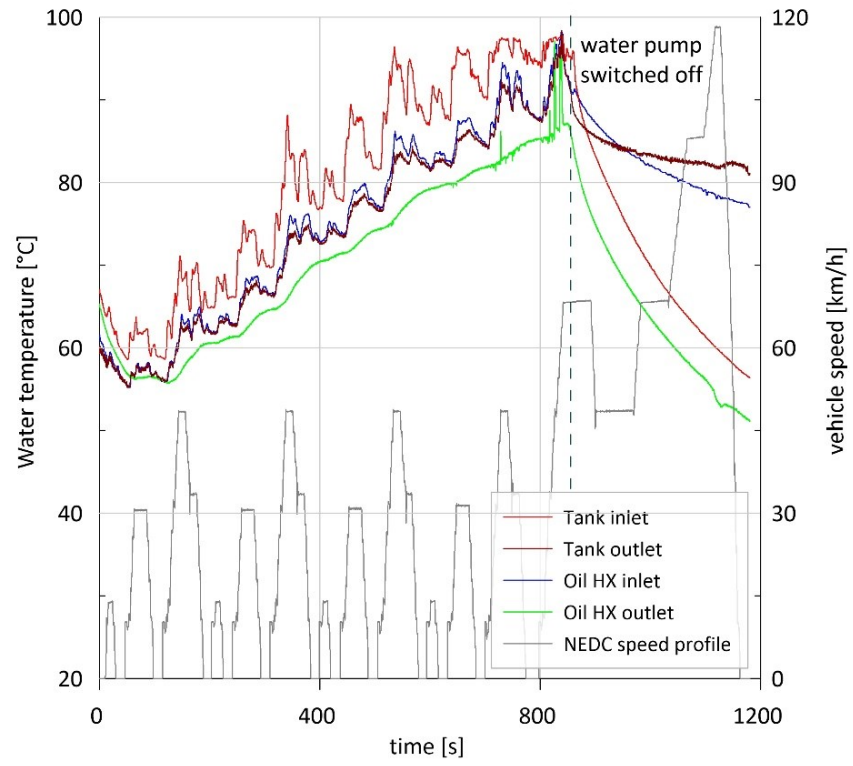

Fig.4. Water thermal profiles.

The engine is always presented with a warmer lubricant (Figure 5): a mean $5{ }^{\circ} \mathrm{C}$ difference is appreciated at the engine inlet, between the situation where the oil is warmed up in the external circuit, with respect to the baseline, where no initial heating takes place. It is worth observing that the temperature difference tends to stabilize after $100 \mathrm{~s}$, suggesting that the advantage in terms of increased oil temperature is appreciated well before the first urban cycle is over.

The same trend is detected on the temperature values of the lubricant oil in the sump, in spite of a lower temperature offset, mostly due to the mixing of the oil with the large mass stored inside the sump: here the temperature shift does not exceed $3{ }^{\circ} \mathrm{C}$ during the whole test run.

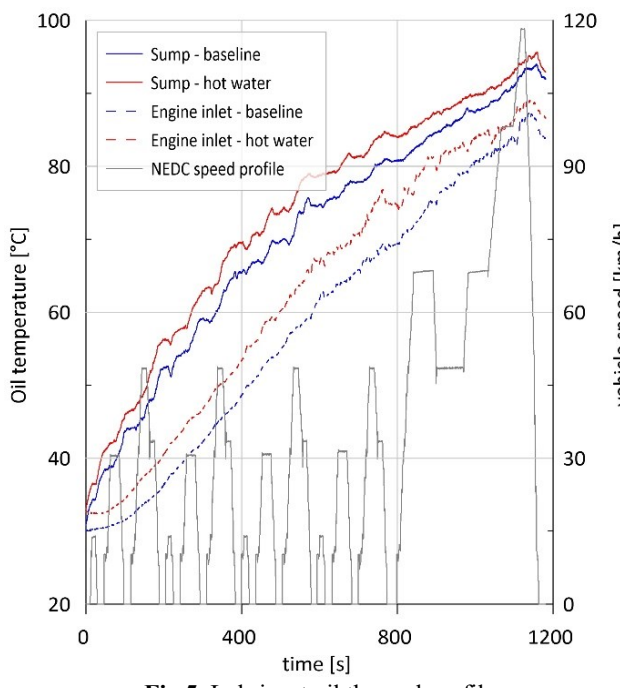

Fig.5. Lubricant oil thermal profile.

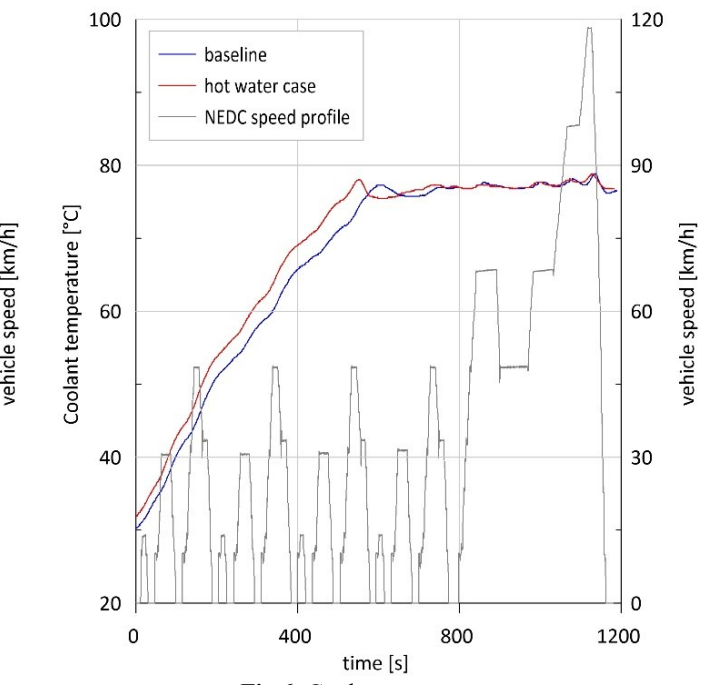

Fig.6. Coolant temperature.

The analysis of the coolant temperature (Figure 6) suggests that, as long as the water warms up the oil, the temperature profile shifts upward $\left(+4^{\circ} \mathrm{C}\right)$ with respect to the baseline. At about $600 \mathrm{~s}$, the coolant stabilizes around temperature values typical of normal operation $\left(75-78^{\circ} \mathrm{C}\right)$ and no difference is appreciated between the baseline situation and the case where hot water is employed. An important assessment is that related to the oil pressure along the external circuit. In fact, when the additional heat exchanger between oil and hot water is introduced, the pressure of the oil at the engine inlet should be 
guaranteed in order to feed the valve, the hydraulic rockers, the chains, and their hydraulic tensioners. Fig.7a shows the pressures of the oil at the engine inlet in both cases, demonstrating only a little suffering (about 0.2 bar lower, Fig. 7b) in the case of "long circuit", i.e. hot water case, with the additional heat exchanger. Higher differences are experienced in the pump outlet (but with positive values, Fig. 7b), which must guarantee the right pressure at engine inlet and, so, is high enough to overcome the pressure drop along the longer external circuit. When the hot water circuit is switched off and heat exchangers bypassed, the pressure levels became similar and the difference between "hot water case" and "baseline" approach a value close to zero (Fig. 7b).

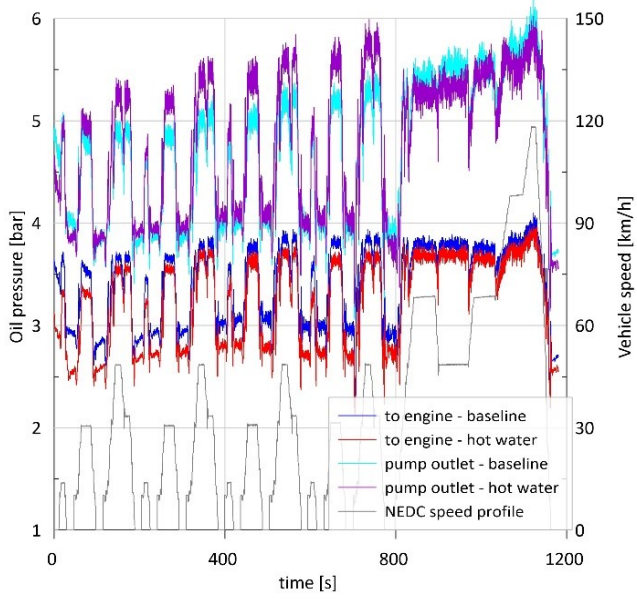

Fig. 7a: oil pressures in the lubricating circuits

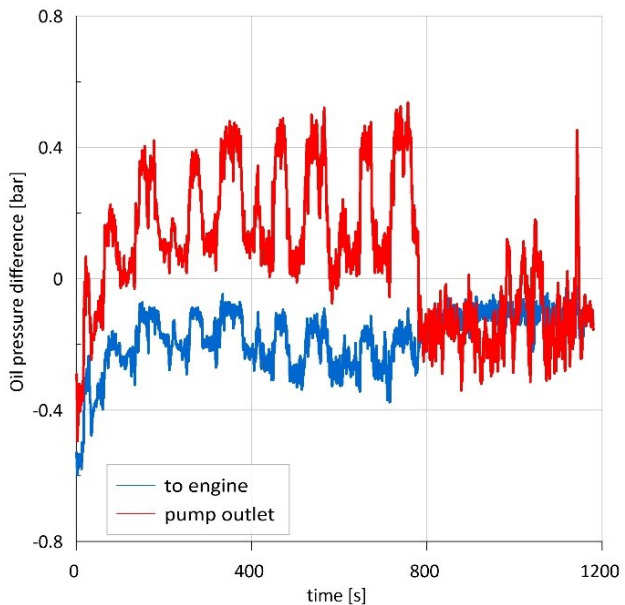

Fig. 7b: oil pressures differences between "hot water" and "baseline" cases

\section{Results and Discussion}

Figure 8 reports the thermal power $\left(P_{t h}\right)$ profiles at the heat exchangers - both water, exhaust, and oil - and the pump of the water circuit, calculated as in eq. 1 for each i-th component.

$$
P_{t h, i}=m \cdot c \cdot\left(T_{\text {out }, i}-T_{\text {in }, i}\right)
$$

Where $m$ is the measured mass flow rate, $c$ is the specific heat of the water $\left(4.187 \mathrm{~kJ} / \mathrm{kg}^{\circ} \mathrm{C}\right)$ and $T$ represents the temperature of the fluid. The water (red line) feeds thermal energy to the oil $-3 \mathrm{~kW}$ mean value - with peaks up to $6 \mathrm{~kW}$ around $400 \mathrm{~s}$ and $700 \mathrm{~s}$, corresponding to the acceleration of the vehicle during urban phases. Negative values in Figure 6 demonstrate that the auxiliary water is giving thermal power to the oil, heating it. The exhaust-to-water heat exchange (blue line) is responsible for a higher thermal power transferred to water, and it plays a crucial role in the enhancement of the warming up of the lubricant [29].

As expected, as the thermal stabilization goes on and the engine temperature rises, the available thermal energy to water increases: during the first $400 \mathrm{~s}$, the average thermal power provided to water never exceeds $7 \mathrm{~kW}$. As the exhaust gases reach higher characteristic temperatures, an average $10 \mathrm{~kW}$ thermal power is available to water, with peaks above $15 \mathrm{~kW}$, around $700 \mathrm{~s}$. The pump (green line) contributes to the water heating, with characteristic values of thermal power lower than $1 \mathrm{~kW}$, up until it is switched off. The balance closes with thermal dispersion through the environment, which could be reduced by a higher level of insulation of each component and piping. 


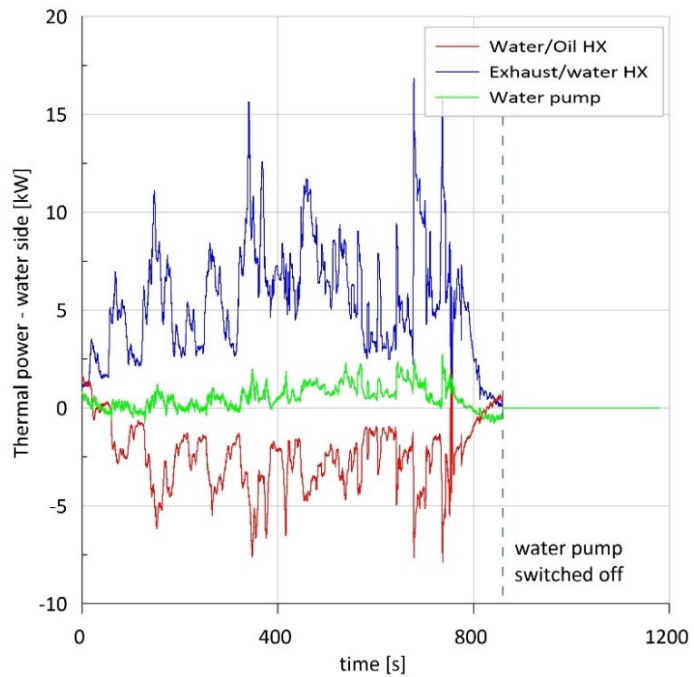

Fig. 8. Thermal power on the water side

The measured fuel consumption is in Figure 9: some advantage in the hundredth liter range is appreciated, despite the additional backpressure for the engine to overcome. The benefits resulted is approximatively $1.7 \%$ of fuel saved and so similar value for $\mathrm{CO}_{2}$ emission reduction. Considering the engine and vehicle considered, this accounts for about 4.4 $\mathrm{gCO}_{2} / \mathrm{km}$. The lower frictional losses, associated with a high performing oil, due to the faster thermal stabilization to characteristic design operating temperatures, seem to overcome the drawbacks - in terms of additional work required to the engine - of having an external circuit for oil heating.

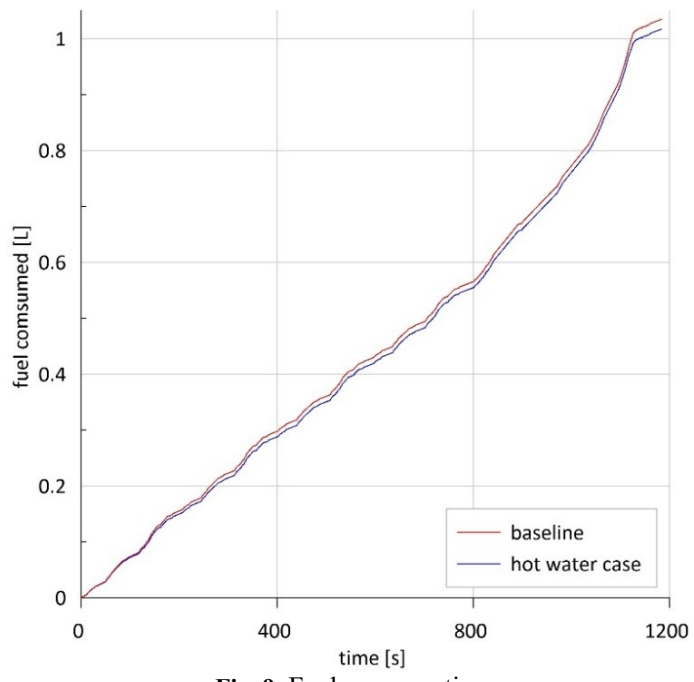

Fig. 9. Fuel consumption

The downside of integrating the engine with a dedicated external circuit for oil heating, plus accounting for an intermediate fluid - water in the present case - is the backpressure the engine needs to overcome. Particularly the heat exchanger on the exhaust path induces highly concentrated pressure drops [30]: in absence of the shell and tube heat exchanger, the engine backpressure stays always between 7 mbar and 25 mbar (Figure 10), between engine start and $800 \mathrm{~s}$. The heat exchanger-induced pressure losses result in a minimum 20 mbar engine backpressure, with peaks around and above 100 mbar. Once the exhaust line no longer feeds the heat exchanging section, the pressure profile matches the regular one, according to the control strategy, which bypasses the exhaust heat exchanger on the gas side when hot water pump is switched off. Hence, extra backpressure resulted is in the maximum range of approximatively 80 mbar, which is still manageable by the engine without an excessive pumping losses increase and, so, with a negligible induced overconsumption $(<1 \%,[31])$ 


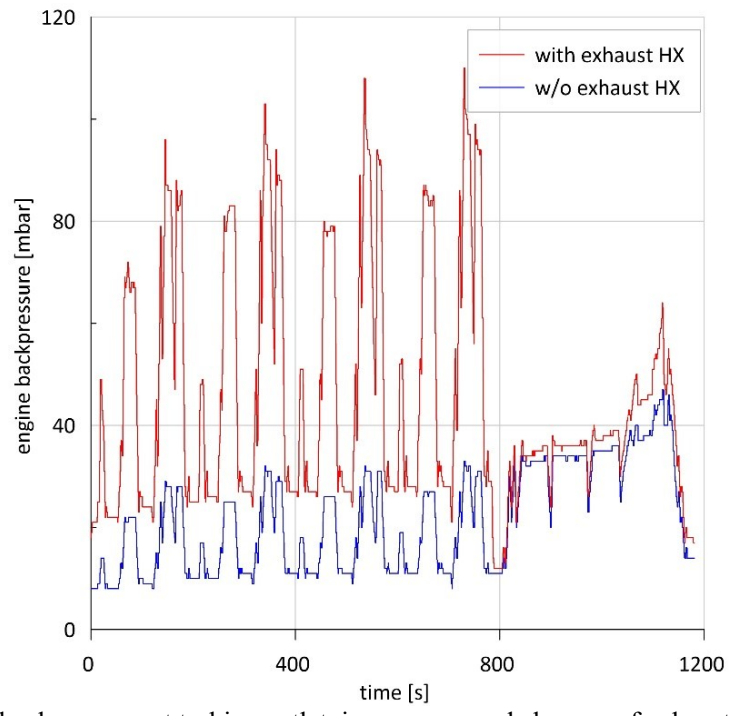

Fig. 10. engine backpressure at turbine outlet, in presence and absence of exhaust heat exchanger

\section{Conclusions}

In this paper, a new technological way to improve engine oil warm up time has been conceived, realized, and studied. A hot thermal storage was considered: it should be sufficiently hot at the starting up of the engine and the vehicle, in order to transfer its thermal energy to the lubricating oil in the very early phase of a driving cycle.

The hot thermal storage considered is a $5 \mathrm{~L}$ tank of water, which can be warmed by a previous utilization of the engine and kept at a certain temperature level by correct insulation of the tank itself. Therefore, an auxiliary hot water circuit is built, in which a heat exchanger between the hot water and the engine lubricant oil is used to heat up the oil, and a second heat exchanger is placed in the exhaust line, in order to favor the re-heating of the water, when the thermal regimentation of the engine is achieved, and to sustain the temperature level of the water during the warming up of the oil.

Thanks to this secondary hot water circuit, an average 3-4 $\mathrm{kW}$ of thermal power has been given to the oil during the four urban phases of the NEDC homologation cycle. Then the hot water circuit is deactivated, since thermal stabilization is close to being reached and oil temperatures approaches to the hot water ones. A reduction of the oil warm up time is achieved in about $100 \mathrm{~s}$, which leads to a faster warm up also of the engine itself and, in particular, of the coolant (-60s). The final results, in terms of fuel consumption reduction and emissions saving are noteworthy: $-1.7 \%$ of fuel used during an NEDC homologation cycle and a corresponding $-4.4 \mathrm{~g} / \mathrm{km}$ of $\mathrm{CO}_{2}$ emissions reduction.

Finally, the technology proposed is simple enough to be introduced on a vehicle. The layout of the hot water circuit can be designed to fit in the engine bay and the initial temperature of the tank can be furtherly optimized by proper insulation. The mechanical power absorbed by the circulating pump can be negligible, since the circuit is at atmospheric pressure and the hydraulic head is, so, very limited. The backpressure at the exhaust can be controlled with suitable heat exchangers technology and flows management.

\section{References}

1. https://ec.europa.eu/growth/sectors/automotive/environment-protection/emissions_en

2. REGULATION EU 2019/631 of The European Parliament and of the Council of 17 April 2019 setting CO2 emission performance standards for new passenger cars and for new light commercial vehicles, and repealing Regulations (EC), No 443/2009 and (EU) No 510/2011 (recast).

3. Regulation (Ec) No 715/2007 Of The European Parliament and of the Council of 20 June 2007 on type approval of motor vehicles with respect to emissions from light passenger and commercial vehicles (Euro 5 and Euro 6) and on access to vehicle repair and maintenance information.

4. Guohui Zhu, Jingping Liu, Jianqin Fu, Zhengxin Xu, Qiyi Guo, He Zhao, Experimental study on combustion and emission characteristics of turbocharged gasoline direct injection (GDI) engine under cold start new European driving cycle (NEDC), Fuel, Volume 215, 2018, Pages 272-284, ISSN 0016-2361, https://doi.org/10.1016/j.fuel.2017.10.048.

5. Gumus, M., "Reducing Cold-Start Emission from Internal Combustion Engines by Means of Thermal Energy Storage System," Applied Thermal Engineering, Vol. 29, No. 4, pp. 652- 660, 2009.

6. Ali Usman, Cheol Woo Park - Transient Lubrication of Piston Compression Ring during Cold Start-Up of SI Engine - International Journal of Precision Engineering and Manufacturing-Green Technology January 2016, Volume 3, Issue 1, pp 81-90. 
7. Shayler, P., Cheng, L., Li, Q., and Wahab, E., "A Modified Oil Lubrication System with Flow Control to Reduce Crankshaft Bearing Friction in a Litre 4 Cylinder Diesel Engine," SAE Technical Paper 2016-01-1045, 2016, doi:10.4271/2016-01-1045.

8. Zammit, J., Shayler, P., Gardiner, R. and Pegg, I., "Investigating the Potential to Reduce Crankshaft Main Bearing Friction During Engine Warm-up by Raising Oil Feed Temperature," SAE Int. J. Engines 5(3):2012, doi: 10.4271/2012-01-1216.

9. Lingjian Chen, Baocheng Du, Li Zhang, Jinlin Han, Bin Chen, Xiaoqi Zhang, Yang Li, Jinbo Zhang, Analysis of real-driving emissions from light-duty gasoline vehicles: A comparison of different evaluation methods with considering cold-start emissions, Atmospheric Pollution Research, Volume 12, Issue 5, 2021, 101065, ISSN 1309-1042, https://doi.org/10.1016/j.apr.2021.101065.

10. C D Rakopoulos, A M Dimaratos, and E G Giakoumis - Investigation of turbocharged diesel engine operation, exhaust emissions, and combustion noise radiation during starting under cold, warm, and hot conditions - Proceedings of the Institution of Mechanical Engineers, Part D: Journal of Automobile Engineering September 2011 vol. 225 no. 9 1118-1133

11. Ali Zare, Timothy A. Bodisco, Mohammad Jafari, Puneet Verma, Liping Yang, Meisam Babaie, M.M Rahman, Andrew Banks, Zoran D. Ristovski, Richard J. Brown, Svetlana Stevanovic, Cold-start NOx emissions: Diesel and waste lubricating oil as a fuel additive, Fuel, Volume 286, Part 2, 2021, 119430, ISSN 0016-2361, https://doi.org/10.1016/j.fuel.2020.119430.

12. Alireza Naderi, Ali Qasemian, Mohammad Hasan Shojaeefard, Saman Samiezadeh, Mostafa Younesi, Ali Sohani, Siamak Hoseinzadeh, A smart load-speed sensitive cooling map to have a high- performance thermal management system in an internal combustion engine, Energy, Volume 229, 2021, 120667, ISSN 0360-5442, https://doi.org/10.1016/j.energy.2021.120667.

13. Mahmoud K. Ashour, Yehia A. Eldrainy, Ahmed E. Elwardany, Effect of cracked naphtha/biodiesel/diesel blends on performance, combustion and emissions characteristics of compression ignition engine, Energy, Volume 192, 2020, 116590, ISSN 0360-5442, https://doi.org/10.1016/j.energy.2019.116590.

14. Vicente Macián, Bernardo Tormos, Vicente Bermúdez, Sophia Bastidas, Development of a floating liner test rig and lubrication model for the study of the piston compression ring friction force under fully flooded and starved lubrication, Tribology International, Volume 160, 2021, 107034, ISSN 0301-679X, https://doi.org/10.1016/j.triboint.2021.107034.

15. Emma Frosina, Adolfo Senatore, Dario Buono, Luigi Arnone, A Critical Analysis on the Lubrication Circuit of a Non-road Diesel Engine by Adopting a 3D and 1D Approaches, Energy Procedia, Volume 81, 2015, Pages 794-804, ISSN 1876-6102, https://doi.org/10.1016/j.egypro.2015.12.086.

16. D. Di Battista, R. Cipollone, Experimental and numerical assessment of methods to reduce warm up time of engine lubricant oil, Applied Energy, Volume 162, 15 January 2016, Pages 570-580, ISSN 0306-2619.

17. Hamedi, M.R., Doustdar, O., Tsolakis, A., Hartland, J. Thermal energy storage system for efficient diesel exhaust aftertreatment at low temperatures, (2019) Applied Energy, pp. 874-887.

18. Sara, H., Chalet, D., Cormerais, M., Hetet, J.-F., Evaluation of hot water storage strategy in internal combustion engine on different driving cycles using numerical simulations, (2018) Proceedings of the Institution of Mechanical Engineers, Part D: Journal of Automobile Engineering, 232 (8), pp. 1019-1035.

19. Alireza Naderi, Ali Qasemian, Mohammad Hasan Shojaeefard, Saman Samiezadeh, Mostafa Younesi, Ali Sohani, Siamak Hoseinzadeh, A smart load-speed sensitive cooling map to have a high- performance thermal management system in an internal combustion engine, Energy, Volume 229, 2021, 120667, ISSN 0360-5442, https://doi.org/10.1016/j.energy.2021.120667.

20. Amireh Nourbakhsh, Morteza Bayareh, Arash Mohammadi, Sadegh Jahantighi, Effect analysis on boiling heat transfer performance of an internal combustion engine at the shutdown time, International Journal of Thermal Sciences, Volume 129, 2018, Pages 365-374, ISSN 1290-0729, https://doi.org/10.1016/j.ijthermalsci.2018.03.022.

21. Ashraf Mimi Elsaid, Experimental study on the heat transfer performance and friction factor characteristics of $\mathrm{Co} 3 \mathrm{O} 4$ and $\mathrm{Al} 2 \mathrm{O} 3$ based $\mathrm{H} 2 \mathrm{O} /(\mathrm{CH} 2 \mathrm{OH}) 2$ nanofluids in a vehicle engine radiator, International Communications in Heat and Mass Transfer, Volume 108, 2019, 104263, ISSN 0735-1933, https://doi.org/10.1016/j.icheatmasstransfer.2019.05.009.

22. Jingjie Cao, Ming Jia, Bo Niu, Yachao Chang, Zhen Xu, Hong Liu, Establishment of an improved heat transfer model based on an enhanced thermal wall function for internal combustion engines operated under different combustion modes, Energy Conversion and Management, Volume 195, 2019, Pages 748-759, ISSN 0196-8904

23. Haoqi Yang, Gequn Shu, Hua Tian, Xiaonan Ma, Tianyu Chen, Peng Liu, Optimization of thermoelectric generator (TEG) integrated with three-way catalytic converter (TWC) for harvesting engine's exhaust waste heat, Applied Thermal Engineering, Volume 144, 2018, Pages 628-638, ISSN 1359-4311, https://doi.org/10.1016/j.applthermaleng.2018.07.091.

24. D. Vittorini, D. Di Battista, R. Cipollone, Engine oil warm-up through heat recovery on exhaust gases - Emissions reduction assessment during homologation cycles, Thermal Science and Engineering Progress, Volume 5, 2018, Pages 412-421, ISSN 24519049, https://doi.org/10.1016/j.tsep.2018.01.010.

25. D. Di Battista, F. Fatigati, R. Carapellucci, R. Cipollone, An improvement to waste heat recovery in internal combustion engines via combined technologies, Energy Conversion and Management, Volume 232, 2021, 113880, ISSN 0196-8904, https://doi.org/10.1016/j.enconman.2021.113880.

26. Shu, G., Hu, C., Tian, H., Li, X., Yu, Z., Wang, M. Analysis and optimization of coupled thermal management systems used in vehicles, (2019) Energies, 12 (7), art. no. en12071265.

27. Jafari, S., Dunne, J. F., Langari, M., Yang, Z., Pirault, J.-P., Long, C. A., \& Thalackottore Jose, J. (2017). A review of evaporative cooling system concepts for engine thermal management in motor vehicles. Proceedings of the Institution of Mechanical Engineers, Part D: Journal of Automobile Engineering, 231(8), 1126-1143. https://doi.org/10.1177/0954407016674606.

28. Di Battista, D., Vittorini, D., Fatigati, F., Cipollone, R., Technical review of opportunities to reduce the warm-up time of lubricant oil in a light-duty diesel engine, (2019) AIP Conference Proceedings, 2191, art. no. 020065,

29. Di Battista, D., Cipollone, R., Fatigati, F., Engine oil Thermal Management: Oil Sump Volume Modification and Heating by Exhaust Heat during ICE Warm Up, (2018) SAE Technical Papers, 2018-April

30. Di Battista, D., Cipollone, R., Improving engine oil warm up through waste heat recovery, (2018) Energies, 11 (1), art. no. 10 ,

31. Di Battista, D., Carapellucci, R., Cipollone, R., Integrated evaluation of Inverted Brayton cycle recovery unit bottomed to a turbocharged diesel engine, (2020) Applied Thermal Engineering, 175, art. no. 115353 